\title{
OS DESAFIOS DA MEDIAÇÃO FAMILIAR NOS CASOS DO DIVÓRCIO E OS EFEITOS DA FRAGMENTAÇÃO DA SOCIEDADE NO VÍNCULO CONJUGAL
}

\section{ARTIGO ORIGINAL}

FILHO, José Alexandrino Saraiva ${ }^{1}$

FILHO, José Alexandrino Saraiva. Os Desafios da Mediação Familiar nos casos do divórcio e os efeitos da fragmentação da sociedade no vínculo conjugal. Revista Científica Multidisciplinar Núcleo do Conhecimento. Ano 04, Ed. 08, Vol. 01, pp. 116126. Agosto de 2019. ISSN: 2448-0959, Link de acesso: https://www.nucleodoconhecimento.com.br/lei/mediacao-familiar

\section{RESUMO}

Pretende o presente ensaio debater os dilemas do artigo 226, $\S 6^{\circ}$ da Constituição Federal de 1988 o divórcio e seus efeitos decorrentes da dissolução da sociedade conjugal no âmbito dos conflitos familiares, nas perspectivas da mediação familiar, abordando seus processos de forma geral, a os métodos e perspectivas resultados nos processos de separação conjugais, as dificuldades presentes na prática profissional, seus processos de alienação parental na atualidade, seus impactos e efeitos sobre os processos psicológicos envolvidos e a breve análise da política de resolução de conflitos.

Palavras-chave: Mediação familiar, dissolução de sociedade conjugal, Constituição Federal/1988, resolução de conflitos, alienação parental.

1 Graduado em Direito pelo Centro Universitário Moacyr Sreder Bastos (MSB). Graduado em Serviço Social pela Universidade Pitágoras - RJ / Graduando em Psicologia pela UFF-RJ. 


\section{INTRODUÇÃO}

O presente ensaio objetiva avaliar a contribuição do método da mediação familiar nos processos de divórcio da sociedade conjugal à luz da Constituição Federal de 1988, seus reflexos nas Políticas Públicas da Família e de Defesa dos Direitos. Para tanto, buscou-se investigar os seguintes aspectos elementares: dificuldades encontradas na prática de mediação na visão de diferentes profisionais que têm contato direto ou indireto com as partes e os operadores de Serviço Social que auxiliam como mediadores que trabalham junto à justiça nas Varas de Família, os aspectos básicos psicológicos dos envolvidos, avaliar as vantagens da mediação na compreensão dos profissionais envolvidos e identificar por meio dos documentos estatístico os desfechos dos casos de dissolução da sociedade e vínculo conjugal atendidos pelos órgãos de resoluções de conflitos.

O método utilizado na pesquisa fora o de natureza qualitativa que permitiu explorar e dimensionar a repercussão dos fatos sobre os sujeitos ou grupos que ainda se dispõe de pouca informação sobre o assunto abordado.

Segundo Minayo (1994), pesquisas de abordagem qualitativa tendem a evidenciar aspectos muitas vezes difíceis de quantificar: sentimentos, motivações, crenças, atitudes e variações nas percepções dos indivíduos (as denominadas visões de mundo, em especial a residência do senso comum).

\section{OS ASPECTOS POLÍTICOS NOS PROCESSOS DE MEDIAÇÃO} FAMILIAR NA DISSOLUÇÃO DE SOCIEDADE E VÍNCULO
CONJUGAL

Sabe-se que durante séculos na história o casamento exerceu a função de promover a posição social e econômica perante a própria sociedade. Com o início da industrialização e o advento da urbanização, o trabalho deixou de centralizar-se no lar e na família e a passou a ser uma unidade autônoma. Em razão deste fato, os casais passaram a esperar do casamento uma fonte de satisfação pessoal e intimidade que atendesse às necessidades do relacionamento conjugal. $E$, na medida em que o 
casamento serve para atender as necessidades emocionais do casal, ao passar do tempo, a própria relação desgastada se torna vulnerável, manifestando a constante indisposição e intolerância ao qual, não se encontra satisfação emocional na sociedade conjugal.

São vários os impactos sociais que têm contribuído nos últimos anos para o aumento significativo nas taxas tanto de reconhecimento quanto dissolução de união estável. Inicialmente, se antes a expectativa de vida juntos, atrelada ao romantismo nas décadas anteriores, em especial as de 70, 80 e 90 faziam que as com que as pessoas permanecessem por mais tempo nas suas relações conjugais, ou seja, o paradigma patriarcal do século XX ainda era submisso ao do século anterior; apenas com melhorias da conquista do feminismo ${ }^{[2]}$.

Segundo Ahons (1995):

(...) ० foco do casamento deixa de ser a posição econômica para enfatizar o amor e o interesse entre duas pessoas, somente no início do século XX, quando o tempo de vida era mais curto, mal se tinha tempo para viver a vida adulta com um único companheiro. (...) na família binuclear os pais moram em residências diferentes, mas procuram conversar para atender suas necessidades e de seus filhos.

Percebe-se a posição considerada que o movimento feminista teve indiretamente uma participação significativa sobre o aumento das taxas de divórcio, pois nas décadas de 60 e 70 a maioria das famílias possuíam apenas um "provedor econômico". Em virtude da entrada da mulher no mercado de trabalho, este possibilitou uma autonomia relativa financeiramente, $e, a$ independência no ponto de vista objetivo, possibilitou o fator de causa a mulher a propositura de pedir o "desquite ${ }^{[3]}$ ", uma vez que não dependia mais de seu marido/companheiro para sustentar a sua prole. Mediante esta decisão, tanto a mulher com o desdobramento desse fator externo, o trabalho, quanto ao homem tinham ambos a possibilidade de tentar satisfazer as suas necessidades em uma outra sociedade conjugal, já que possuíam um longo período de vida. "As mulheres trabalham e são mais independentes financeiramente. Porque um casal que não se ama deve continuar junto, quando não tem pela frente 30 ou 40 anos de vida? $"$. 
Acentua Osório (2002), que em decorrência das transformações culturais ao longo dos anos, o movimento socioeconômico e o processo civilizatório mudaram ao longo dos séculos as expectativas, necessidade e desejos dos casais. Essa própria dinâmica das relações conjugais, hoje, passou a se constituir um conjunto, no qual cada elemento constitutivo conserva suas propriedades independente da presença de outro. Para tanto, observa-se a transição da constituição de aquilo que era em "conjunto", as transmissões dessas etapas passaram a modificar também as estruturas psíquicas e as estruturas emocionais; o fenômeno natural da autonomia passa a fazer parte do rol de expectativas de direitos.

A dissolução da sociedade conjugal envolve sentimentos em meio ao sofrimento e angústia de ambos os lados; o mediador ${ }^{[4]}$ com sua capacitação técnica vivencia as complicações de ordem emocional vividos pelos casais em crise e em processo de separação. A mediação serve como um auxílio técnico na reorganização do sistema familiar, em virtude da transição familiar para a binuclear. Com efeito, a separação rompe o vínculo matrimonial se não haver filhos, mas se houver, segmenta-se a guarda compartilhada de modo que os filhos possam beneficiar-se ao modo que o relacionamento mesmo rompido, passa a ser de colaboração e apoio em relação aos filhos, e estes por sua vez, passam a vivenciar o rompimento conjugal com atenuantes se os efeitos vinculantes não haver problemas ao acordo de natureza jurídica alimentícia, ou seja, os pais passam a ser parceiros nos cuidados das obrigações parentais, reforçando positivamente os laços de relação familiar. A guarda compartilhada é fundamental para garantir ao menor a convivência com ambos os pais.

\section{OS DESAFIOS ATUAIS PARA AÇÕES AFIRMATIVAS E A NECESSIDADE DAS POLÍTICAS PÚBLICAS REPARATÓRIAS NO ÂMBITO FAMILIAR}

As ações afirmativas na esfera familiar são medidas especiais tomadas com o objetivo de assegurar progresso adequado de certos grupos, sociais ou indivíduos que necessitem de proteção que possam ser necessárias e úteis para proporcionar a tais 
grupos ou indivíduos, igual gozo ou exercício de direitos humanos e liberdades fundamentais, contanto que, tais medidas não conduzam em consequência, à manutenção de direitos separados para diferentes grupos, e não prossigam após terem sido alcançados os seus objetivos. A possibilidade da adoção de ações afirmativas tem amparo nos arts. 3ำ e 5ambos da Constituição Federal/88 e, integrada ao nosso ordenamento jurídico pelo Decreto n. 65.810/69.

Vale ressaltar que a implementação de políticas públicas no patamar de resolução de conflitos familiares são indispensáveis para a garantia de relevantes direitos constitucionais. Buscam realinhar os meios de acesso e formas de competitividade a fim de assegurar condições para que grupos raciais, sociais ou étnicos, bem como indivíduos que necessitam da proteção específica do Estado, possam exercer os direitos consagrados na Constituição da República .

As mudanças trazidas na legislação brasileira, especificamente por meio da Resolução $n^{\circ} 125$ do Conselho Nacional de Justiça, e da Lei 13.105/15, os principais pontos abordados, como conceitos e princípios. A temática ganha relevo, especialmente, diante do contexto atual, já que está prestes a vigorar o Novo Código de Processo Civil, Lei $13.105 / 2015^{[5]}$, e que por meio dela se cria uma grande expectativa de melhor funcionamento do Poder Judiciário.

De acordo de Reinaldo Dias e Fernanda Matos ${ }^{[6]}$, políticas públicas podem ser entendidas como "um meio de concretização dos direitos que estão codificados nas leis de um país". É o estabelecimento de metas e estratégias que visam à solução dos problemas públicos ou à "obtenção de maiores níveis de bem-estar social”.

Nos núcleos de prática jurídica seja das universidades ou dos centros judiciários, por exemplo, a parte requerente pode solicitar de forma presencial ou on-line um atendimento e sendo convocada a parte requerida lhe é explicado as vantagens de construir uma solução consensual, e ainda a alerta para a morosidade e o desgaste emocional que irá enfrentar em uma demanda judicial, acaba aceitando a ideia de participar das sessões de mediação e conciliação. Contudo, muitas vezes por 
ressentimento, magoa ou ainda por não ter confiança no método aplicado fora do judiciário acaba se ingressando na via judicial.

Com a previsão da audiência de mediação e conciliação no Novo Código de Processo Civil em seu artigo $334^{[7]}$, se dará mais uma oportunidade as partes entrarem em um consenso. Além disso, se ambas as partes não tiverem interesse a audiência esta não será realizada, conforme parágrafo $4^{\circ}$, inciso $\mathrm{l}$, do mesmo diploma legal, demonstra que não se pretende pressionar as partes para que entrem num acordo. Com isso, parece que o objetivo de institucionalizar a mediação e conciliação é dar alternativas as partes, e trazer a elas o conhecimento da existência dos meios compositivos, e não regulamentar seus procedimentos, ou impor as partes o seu uso.

É evidente que as Políticas afirmativas no sentido macro, quando endereçadas a combater genuínas situações fáticas incompatíveis com os fundamentos e princípios do Estado Social, ou a estes dar consistência e eficácia, em nada lembram privilégios, em nem com eles se confundem; em vez de funcionarem por exclusão de sujeitos de direitos, estampam nos seus objetivos e métodos a marca da valorização da inclusão, sobretudo daqueles aos quais se negam os benefícios mais elementares do patrimônio material e intelectual histórica. Frequentemente, para privilegiar basta a manutenção do status quo, sob o argumento de autoridade do estrito respeito ao princípio da igualdade.

Segundo Laura (2007, p. 86):

(...) Cabe apontar novamente que estas afirmações não são só propositivas, mas operativas. Não há forma de lutar efetivamente contra a discriminação, se não se tecem redes de seguridade social universais com maiores impactos sobre os grupos sociais menos autônomos.(..) A saída não está em ações isoladas que busquem alívios transitórios de danos irreparáveis, mas em políticas estáveis que contenham as condições necessárias para evitar que as pessoas cheguem à marginalidade e exclusão. Estas redes deveriam funcionar de forma permanente para dar garantias desde o nascimento a cada cidadão.

Como se observa, nesse entendimento, por políticas afirmativas, não é somente um conjunto de propostas e medidas voltadas a reparar injustiças sociais à determinados 
grupos historicamente discriminados pela exclusão; ao contrário, uma declara a outra em resultados; embora cada uma tenha sua densidade própria, o que significa dizer que por política afirmativa esta tem enquadramento em uma ordem de importância ativa e real, quanto a política pública reparatória ela é de ajuste social, visa o tratamento em defesa da estabilidade face o subemprego, ou seja, ela tem por função a responsabilidade social, inclusive quando se tratar esta nos efeitos de sequelas de conflitos das relações familiares.

É importante ressaltar, que as políticas públicas reparatórias no âmbito familiar são ações criadas com prazos determinados, ou seja, duram um determinado período de forma preventiva e reparadora, para criar equilíbrio e oportunidades às pessoas de obter uma paz no mínimo interior.

Para isso, os meios consensuais não devem ser utilizados como medidas imediatistas, objetivando a extinção dos processos judiciais em grande quantidade, mas sim como política pública de longo prazo, visando a mudança cultural, bem como método preventivo de surgimento de novos conflitos.

Mas é preciso que as ações afirmativas não fiquem no acaso, no plano institucional e burocrático, sua aderência deve ser absoluta, é buscar a consciência das responsabilidades inerentes à paternidade e maternidade por meio de ações que propiciem uma maior participação destes grupos na educação dos filhos, e minimizar as dificuldades de prováveis ecos de ordem sentimental.

\section{OS CONFLITOS FAMILIARES E O PROBLEMA DA ALIENAÇÃO} PARENTAL

A própria Lei oํ 12.318 10, reza em seus artigos que dispõe sobre Alienação Parental, combinado com a Lei 8.069/90 - Estatuto da Criança e do Adolescente - é o diploma legal regulamentador que prevê a proteção integral das crianças e adolescentes, recaindo tal obrigação às famílias, à União, Estados e Municípios e a sociedade, nos termos do art. 227, caput, da Constituição Federal de 1988. 
É sabido que a ruptura de uma relação conjugal sempre é um momento desgastante para a família; pois exige a elaboração de novas planilhas de vida para pais e filhos, além da divisão de bens, do pagamento de pensão, e de outras questões. Tais acontecimentos, frequentemente, vêm precedidos de divergências e discussões, relacionadas a fatores de ordem psicológica e social.

Todas as demandas jurídicas tradicionais até hoje, tem sido insuficiente para o atendimento de todo um contingente processual físico instalado em nosso tribunais brasileiros. O advento da Resolução $125 / 10$ do $\mathrm{CNJ}$, fora determinante para o surgimento do Mediador (um terceiro imparcial), que iria propor às partes e facilitando a comunicação para que o casal em conflito encontrasse alternativas que fossem dos seus interesses e de seus filhos, chegando a um possível acordo. Nessa dialética pacífica, os pais são ajudados a entender as necessidades dos filhos e a desenvolver um relacionamento cooperativo nas questões ligadas à parentalidade.

Nesse percurso pré-processual, entendemos por "construção de um problema social" o processo interno pelo qual um determinado grupo familiar quando a situação em que se encontram seus integrantes, é considerada por alguma razão, socialmente problemática, sendo pessoas ${ }^{[8]}$ que ameaçam a paz pública, ou que devem ser especialmente protegidas, ou que não devem ser discriminadas, etc.

Cabe ao mediador com técnicas de argumentação no curso da instrução verificar que do outro lado se encontra alguém que também está praticando outro tipo de abuso, o de natureza moral. Nesse caso, aplica-se as medidas de proteção à criança e/ou adolescente, que se encontra em situação concreta de risco e vêm sofrendo, reiteradamente, abusos sejam de ordem física e/ou moral por parte dos genitores que, em tese, após a ampla defesa, se constatado o abuso, poderão até ser destituídos do poder familiar, nos termos da Lei 8.069/90.

Assim, a partir do ECA, ao mesmo tempo em que observamos um processo de revalorização do grupo familiar, na medida em que este é definido pela legislação como o espaço social privilegiado para a socialização humana ${ }^{[9]}$, quando as características das famílias atendidas passam a ser visualizadas, dão margem para 
que a família seja qualificada como negligente, agressora, etc, ou seja, inadequada para o desenvolvimento da criança e do adolescente e incapaz de assegurar-Ihes os direitos definidos pelo ECA, Conforme alerta Soares, dependendo do critério utilizado para medir, por exemplo, a "negligência", "(...) corre-se o risco de incriminar boa parte da população de baixa renda que não consegue vestir, alimentar e cuidar apropriadamente de sua prole" (SOARES, 1997).

\section{CONCLUSÃO}

Conforme analisado, a Mediação Familiar está, aos poucos, adaptando-se à era da solução de litígios. As comprovações desta afirmação podem ser realizadas mediante a análise da natureza das demandas demonstra que a experiência de negociação poderá ter sucesso imediato, se conduzida por mediadores experientes.

Para tanto, ocorrendo a mudança de paradigma de pensamento cultural, consequentemente, irá diminuir descrédito dirigido ao Judiciário, e as partes terão oportunidade de vir a solucionar seus litígios em prazo célere.

Entretanto, o certo é que muito ainda há de ser realizado. Além da necessidade da criação e aprimoramento de diversas outras políticas públicas relacionadas à educação saúde, trabalho, saneamento básico e outros, verifica-se que a própria cultura de judicialização apresenta diversos obstáculos, que não foram minuciosamente analisados no presente ensaio por necessidade de corte epistemológico, mas que são igualmente relevantes para que se possa avançar nesta matéria. As discussões e as controvérsias sobre o tema são inevitáveis. Por isso o debate mostra-se relevante e deve ser estimulado.

Consideramos que as políticas públicas de proteção aos direitos poderão ser mais eficazes na medida em que seus agentes empreendam um esforço de diálogo com a população demandante, levando em conta a existência de diferenças culturais quanto à organização familiar e aos valores dominantes nas diferentes classes sociais. Devese enfatizar a importância da mediação na resolução dos litígios inerentes à referida matéria, mediante a conclusão de acordos, a fim de evitar a interposição de reiterados 
recursos, cujos resultados revelam-se inócuos e desastrosos para a família, além de contribuírem para o atravancamento das pautas de julgamentos.

A viabilidade disso implica a compreensão das diferenças não como a causa dos problemas sociais, mas como um dos resultados de uma sociedade marcada pela desigualdade. Embora a caminhada seja longa, a chegada nunca se torna possível sem os primeiros passos.

\section{REFERÊNCIAS}

AHRONS, Constance. O bom divórcio: como manter a família unida quando o casamento termina. Rio de Janeiro: Objetiva, 1995.

BRASIL. Lein¹3105, de 16 de março de 2015. Institui o Código de Processo Civil. Brasília: Senado Federal, 2015. Disponível em: http://www.planalto.gov.br/ccivil_03/_Ato2015-2018/2015/Lei/L13105.htm. Acesso em: 20. abr.2018.

BRASIL. Resolução n 125 de 29 de novembro de 2010. Institui a Política Judiciária Nacional de tratamento adequado dos conflitos de interesses no âmbito do Poder Judiciário e dá outras providências. Brasília: Conselho Nacional de Justiça, 2010.

DIAS, Reinaldo; MATOS, Fernanda. Políticas Públicas: Princípios, propósitos e processos. São Paulo: Atlas, 2011.

CÂMARA DOS DEPUTADOS. http://www2.camara.leg.br/legin/fed/decret/19601969/decreto-65810-8-dezembro-1969-407323-norma-pe.html. Acesso em 12 abr. 2018.

CONSELHO NCAIONAL NUSTIÇA. http://www.cnj.jus.br/images/stories/docs_cnj/resolucao/arquivo_integral_republicaca o_resolucao_n_125.pdf. Acesso em: 20.abr.2018.

ESTATUTO da criança e do adolescente: lei 8069/90 (1990). Brasília. 
FERNANDES, José Antônio da Costa. Política Pública da Família e de Defesa dos Direitos. Valinhos: 2015. https://www.colaboraread.com.br/aluno/conteudoweb/index/1124989001?atividadeDi sciplinald=5484010. Acesso02/04/2018.

LEI № 12.318, DE 26 DE AGOSTO DE 2010. Disponível em: http://www.alienacaoparental.com.br/lei-sap. Acesso em 12 abr. 2018.

MASOTTI, Viviane. Direitos e Seguridade Social. Valinhos: 2015.

MINAYO, M. C. Ciência, técnica e arte: o desafio da Pesquisa Social. In: (Org.) Pesquisa social: teoria, método e criatividade. Petrópolis: Vozes, 2001, p. 0930.

. O desafio do conhecimento. São Paulo/Rio de Janeiro: HUCITECABRASCO, 1994.

OSÓRIO, Luís Carlos; VALLE, Maria Elizabeth do. op. cit., 2002.

PAUTASSI, Laura C. Há igualdade na desigualdade? Abrangência e limites das ações afirmativas. Sur, Rev. int. direitos human. [online]. 2007, vol.4, n.6, pp.70-93. ISSN 1806-6445. Disponível em: https://sur.conectas.org/wpcontent/uploads/2017/11/sur6-port-laura-c-pautassi.pdf. Acesso12 setembro de 2017.

VALLE, Maria Elizabeth do. Terapia de famílias - novas tendências. São Paulo: Artmed, 2002.

WIKIPEDIA. https://pt.wikipedia.org/wiki/Desquite. Acesso em: 14 abr. 2018.

\section{APÊNDICE - REFERÊNCIAS DE NOTA DE RODAPÉ}

2. "Entre as décadas de 1930 e 1960, muitas manifestações feministas oscilavam mediante as mudanças desenvolvidas no cenário político nacional. Essa revolução dos costumes engendrada na década de 1960 abriu caminho para que o feminismo se tornasse um movimento de maior força e combatividade. Mesmo sob o contexto da 
ditadura, as mulheres passaram a ter um posicionamento crítico e se organizar para questionarem mais profundamente seu papel assumido na sociedade. A problemática dos padrões de comportamento passou a andar de mãos dadas com os ideias de esquerda que inspiravam várias personalidades participantes desse movimento.

3. Desquite é um termo do direito que era usado para designar as separações matrimoniais antes da instituição do divórcio. Equivale à atual separação, na qual ocorre a separação dos cônjuges e de seus bens, mas não ocorre a dissolução do vínculo matrimonial

4. Para atuar como mediador judicial é necessário ser graduado há pelo menos dois anos em qualquer área de formação, nos moldes do art. 11 da Lei n. 13.140, de 26 de junho de 2015 (Lei da Mediação). A Resolução n. 125/2010 do CNJ, a Lei da Mediação e o Novo Código de Processo Civil (NCPC - Lei 13.105/2015) determinam que o mediador e o conciliador judicial devem ter capacitação, por meio de curso realizado por entidade credenciada e reconhecida, em conformidade com os parâmetros curriculares definidos pelo Conselho Nacional de Justiça em conjunto com o Ministério da Justiça.

5. Cabe informar que o novo Código de Processo Civil, no artigo 167, parágrafo $5^{\circ}$ veda o exercício da advocacia pelos mediadores e conciliadores no juízo em que desempenhem suas funções.

6. DIAS, Reinaldo; MATOS, Fernanda. Políticas Públicas: Princípios, propósitos e processos. São Paulo: Atlas, 2011, p. 15.

7. "Art. 334 NCPC. - Se a petição inicial preencher os requisitos essenciais e não for o caso de improcedência liminar do pedido, o juiz designará audiência de conciliação ou de mediação com antecedência mínima de 30 (trinta) dias, devendo ser citado o réu com pelo menos 20 (vinte) dias de antecedência.

$\S 1^{\circ} \mathrm{O}$ conciliador ou mediador, onde houver, atuará necessariamente na audiência de conciliação ou de mediação, observando o disposto neste Código, bem como as disposições da lei de organização judiciária. 


\section{$(\ldots)$}

§ 7ํㅗ A audiência de conciliação ou de mediação pode realizar-se por meio eletrônico, nos termos da lei."

8. "Art. $6^{\circ}$ Caracterizados atos típicos de alienação parental ou qualquer conduta que dificulte a convivência de criança ou adolescente com genitor, em ação autônoma ou incidental, o juiz poderá, cumulativamente ou não, sem prejuízo da decorrente responsabilidade civil ou criminal e da ampla utilização de instrumentos processuais aptos a inibir ou atenuar seus efeitos, segundo a gravidade do caso:

I - declarar a ocorrência de alienação parental e advertir o alienador;

II - ampliar o regime de convivência familiar em favor do genitor alienado;

III - estipular multa ao alienador;

IV - determinar acompanhamento psicológico e/ou biopsicossocial;

V - determinar a alteração da guarda para guarda compartilhada ou sua inversão;

VI - determinar a fixação cautelar do domicílio da criança ou adolescente;

VII - declarar a suspensão da autoridade parental.

Parágrafo único. Caracterizado mudança abusiva de endereço, inviabilização ou obstrução à convivência familiar, o juiz também poderá inverter a obrigação de levar para ou retirar a criança ou adolescente da residência do genitor, por ocasião das alternâncias dos períodos de convivência familiar. Como se observa, a imposição no art. $6^{\circ}$ da Lei 12.318/90 não exclui a verificação da responsabilidade civil ou criminal do alienante."

9. "Art. 19 - Toda criança ou adolescente tem direito a ser criado e educado no seio da sua família e, excepcionalmente, em família substituta, assegurada a convivência 
familiar e comunitária, em ambiente livre da presença de pessoas dependentes de entorpecentes" (ESTATUTO 1990)."

Enviado: Abril, 2018.

Aprovado: Agosto, 2019. 